\title{
CARBONO ORGÂNICO E NITROGÊNIO TOTAL DO SOLO E SUAS RELAÇÕES COM OS ESPAÇAMENTOS DE PLANTIO DE CAFEEIRO ${ }^{(1)}$
}

\author{
Otacílio José Passos Rangel ${ }^{(2)}$, Carlos Alberto Silva ${ }^{(3)}$, Paulo Tácito \\ G. Guimarães ${ }^{(4)}$, Leônidas Carrijo Azevedo Melo ${ }^{(5)}$ \& Antônio Claret \\ de Oliveira Junior ${ }^{(6)}$
}

\begin{abstract}
RESUMO
A densidade de plantio e o arranjo das plantas exercem influência sobre a produção de resíduos vegetais nos agroecossistemas cafeeiros. Esse aporte diferenciado de resíduos regula os teores de $\mathrm{C}$ e $\mathrm{N}$ do solo. Este trabalho objetivou avaliar os teores de $\mathrm{C}$ orgânico e de $\mathrm{N}$ total em um Latossolo Vermelho distrófico cultivado com cafeeiro com diversos espaçamentos de plantio. $\mathrm{O}$ experimento foi conduzido no período de 1992 a 2004 na Fazenda Experimental da EPAMIG, em Machado (MG). Os tratamentos avaliados consistiram da combinação de quatro espaçamentos entre linhas $(2,0 ; 2,5 ; 3,0 ; \mathrm{e} 3,5 \mathrm{~m})$, três espaçamentos entre plantas $(0,5 ; 0,75 ;$ e $1,0 \mathrm{~m})$ e dois sistemas de manejo dos resíduos culturais (entrelinha - EL e projeção da copa - PC), totalizando 24 tratamentos, dispostos no campo em blocos ao acaso, em esquema fatorial $4 \times 3 \times 2$, com três repetições. Foram avaliados os teores de $\mathrm{C}$ orgânico (CO) e de $\mathrm{N}$ total do solo (NT), além da relação CO/NT. Nas amostras de solo da EL, os teores de CO e NT foram maiores do que os da PC. O espaçamento de plantio influenciou os teores de $\mathrm{CO}$, com os maiores valores, em geral, no espaçamento de 3,5 m entre as linhas de plantio, quando a distância entre plantas foi de 0,5 e $0,75 \mathrm{~m}$, na profundidade de $0-0,05 \mathrm{~m}$. O maior acúmulo de resíduos vegetais, o menor revolvimento do solo e, conseqüentemente, os maiores teores de matéria orgânica favorecem a ocorrência de maiores teores de CO e NT
\end{abstract}

\footnotetext{
(1) Trabalho financiado pelo Consórcio Brasileiro de Pesquisa e Desenvolvimento/Café e pela Embrapa Café. Recebido para publicação em dezembro de 2005 e aprovado em agosto de 2008.

(2) Professor da Escola Agrotécnica Federal de Alegre - EAFA. Doutor em Solos e Nutrição de Plantas. Caixa Postal 47, CEP 29520-000. Alegre (ES). E-mail: otaciliorangel@yahoo.com.br

(3) Professor Adjunto do Departamento de Ciência do Solo, Universidade Federal de Lavras - UFLA. Caixa Postal 3037, CEP 37200000 Lavras (MG). E-mail: csilva@ufla.br

(4) Pesquisador da Empresa de Pesquisa Agropecuária de Minas Gerais/CTSM. Caixa Postal 176, CEP 37200-000 Lavras (MG). E-mail: paulotgg@ufla.br

(5) Doutorando em Solos e Nutrição de Plantas, Escola Superior de Agricultura Luiz de Queiroz - ESALQ. Av. Pádua Dias 9, CEP 13418-900 Piracicaba (SP). E-mail: leonidasmelobr@yahoo.com.br

${ }^{(6)}$ Doutor em Solos e Nutrição de Plantas pelo Departamento de Ciência do Solo, UFLA. E-mail: antoniocoliveirajr@yahoo.com.br
} 
na EL. A retirada da mata e o cultivo do solo com cafeeiro por 11 anos resultou em decréscimo nos teores de CO de $26 \%$ a $38 \%$ na EL e na PC, respectivamente, e diminuição média de $25 \%$ nos teores de NT.

Termos de indexação: Coffea arabica L., densidade de plantio, matéria orgânica do solo.

\title{
SUMMARY: SOIL ORGANIC CARBONAND TOTAL NITROGENAS RELATED WITH COFFEE SPACING
}

\begin{abstract}
The density and arrangement of trees influences the production of plant residues in coffee agroecosystems. This differentiated input of biomass regulates the contents of soil$C$ and $-N$. This study aimed to evaluate the contents of organic $C$ and total $N$ in a Typic Hapludox, in different spacings of (Coffea arabica L.) trees and tree rows. The experiment was carried out from 1992 to 2004 on an experimental farm of EPAMIG, in Machado (Minas Gerais State, Brazil). The treatments consisted of the combination of four distances between tree rows $(2.0 ; 2.5 ; 3.0$ and $3.5 \mathrm{~m})$, three in-row distances $(0.5 ; 0.75$ and $1.0 \mathrm{~m})$ and two management systems of crop residues (interline - IL and canopy projection - CP), totaling 24 treatments, arranged randomly in the field in blocks, in 4x3x2 factorial design, with three replications. The soil organic carbon $(O C)$ and total nitrogen (TN) contents were measured, apart from the OC/TN ratio. In samples collected in IL, the OC and TN contents were higher than those measured in CP. The cropping spacing influenced the OC contents; highest values were verified when distance between rows was $3.5 \mathrm{~m}$ and in-row distances 0.75 and $0.5 \mathrm{~m}$, in the $0-0.05 \mathrm{~m}$ layer. Higher accumulation of plant residues, low soil disruption, and, consequently, higher contents of organic matter favors more OC and TN in the IL. Deforestation and coffee cropping for 11 years resulted in decreasing OC contents from $26 \%$ to $38 \%$, in $I L$ and $C P$, respectively, and an average reduction of $25 \%$ for $T N$.
\end{abstract}

Index terms: Coffea arabica L., planting density, soil organic matter.

\section{INTRODUÇÃO}

O sul do Estado de Minas Gerais tem a maior área de produção de café do Brasil. Inicialmente, a expansão das lavouras nessa região caracterizou-se pela substituição de grande parte da vegetação nativa por áreas cultivadas com cafeeiro, em sistemas de plantio com cerca de 1.500 a 3.000 plantas ha-1. Nos últimos anos, tem havido tendência de os plantios serem mais adensados, a ponto de serem notados estandes de até 10.000 plantas ha-1. A substituição de ecossistemas naturais por agroecossistemas, com culturas introduzidas, envolve uma série de atividades que reduzem o aporte de biomassa e aumentam as perdas de $\mathrm{C}$ do sistema solo por erosão, decomposição e lixiviação (Lal, 2001; Zinn et al., 2005). As alterações na matéria orgânica do solo (MOS) têm conseqüências sobre as propriedades químicas, físicas e biológicas do solo e se mostram dependentes das condições do solo, do clima e das práticas culturais adotadas (Marchiori Junior \& Melo, 2000). Estudos que abordem o impacto da implantação de novos sistemas de manejo do solo e de culturas sobre as propriedades químicas, físicas e biológicas do solo são importantes no sentido de avaliar a sustentabilidade de diferentes agroecossistemas em uma região.
Em áreas cultivadas, os teores de MOS dependem das taxas de adição de resíduos e da intensidade dos processos de decomposição da MO. No Brasil, quando a vegetação perene nativa de uma região é substituída por sistemas agrícolas, os teores de MO são reduzidos, sendo registradas perdas de $80 \%$ dos estoques iniciais de MO na camada superficial do solo, em período de cinco anos de cultivo (Silva et al., 1994). Em solos de regiões tropicais, as perdas de $\mathrm{C}$ observadas após a retirada da vegetação natural e cultivo dos solos são mais aceleradas do que em regiões temperadas (Mielniczuk et al., 2003). Nos trópicos, temperaturas mais elevadas, altos índices pluviométricos e maior atividade microbiana causam rápida decomposição dos materiais orgânicos incorporados e presentes no solo (Longo \& Espíndola, 2000).

Por exercer papel importante no aporte de resíduos e na disponibilidade de luz e água, o número de plantas em lavouras cafeeiras exerce papel importante nos teores de $\mathrm{C}$ em diferentes compartimentos da MOS. Isso ocorre em decorrência do aumento da densidade de plantio em lavouras cafeeiras promover um incremento no aporte de resíduo vegetal produzido por unidade de área, o que implica maior adição de $\mathrm{C}$ ao solo na forma de raízes, folhas, ramos, ácidos orgânicos, exsudatos e mucilagens (Pavan \& Chaves, 
1996). De acordo com Beer (1998), em sistema de plantio adensado de cafeeiro, podem ser acumuladas até $14 \mathrm{t} \mathrm{ha}^{-1} \mathrm{ano}^{-1}$ de resíduos, que se originam da queda de folhas e de material podado. Arato et al. (2003) observaram que $50 \%$ do material depositado sobre o solo em área de cultivo de cafeeiro foi decomposto no período de 215 dias, indicando rápida liberação e reaproveitamento dos nutrientes contidos nos resíduos vegetais. Dessa forma, os teores de $\mathrm{C} \mathrm{e}$ $\mathrm{N}$ total podem ser alterados, em maior ou menor intensidade, dependendo do sistema de plantio adotado (Pavan \& Chaves, 1996).

Os teores de N, nas diferentes profundidades do solo, apresentam o mesmo padrão de distribuição dos teores de C, com os maiores valores observados em camadas mais superficiais do solo, onde há maior acúmulo de MO, sendo, dessa forma, também influenciados pelos sistemas de plantio do cafeeiro. Em solos agrícolas, os teores de $\mathrm{N}$ variam, em geral, de 0,02 a $0,5 \%$, e $98 \%$ do $\mathrm{N}$ total encontra-se na forma orgânica (Stevenson, 1994). A relevância da inclusão do $\mathrm{N}$ nos estudos que avaliam a MOS reside no fato de os compostos orgânicos representarem um importante reservatório de formas de $\mathrm{N}$ potencialmente disponíveis para as culturas (Stevenson, 1994; D’Andréa et al., 2004). Apesar da crescente adoção de menores espaçamentos nas lavouras cafeeiras, ainda são poucas as informações sobre as alterações nas propriedades do solo, principalmente as relacionadas aos teores de $\mathrm{C}$ e N, decorrentes da utilização de diferentes espaçamentos de plantio.

Este trabalho teve por objetivo avaliar os teores de $\mathrm{C}$ orgânico e de $\mathrm{N}$ total em um Latossolo Vermelho distrófico cultivado com cafeeiro (Coffea arabica L.) sob diferentes espaçamentos de plantio, na região sul de Minas Gerais.

\section{MATERIAL E MÉTODOS}

\section{Caracterização da área experimental}

O experimento foi realizado na Fazenda Experimental da Empresa de Pesquisa Agropecuária de Minas Gerais (EPAMIG), localizada a 10 km do município de Machado (MG). O clima da região local foi classificado como Aw (tropical estacional de savana) no sistema de Köppen, com inverno seco e verão quente. A temperatura média anual do município é de $21^{\circ} \mathrm{C}$ (média mínima de $15^{\circ} \mathrm{C}$ em julho e máxima de $27^{\circ} \mathrm{C}$ em janeiro) e a precipitação pluvial média anual, de $1.670 \mathrm{~mm}$, com as chuvas concentradas de outubro a abril. O solo da área experimental foi classificado como Latossolo Vermelho distrófico textura média. No início do experimento, o solo apresentava, na camada de $0-0,2 \mathrm{~m}, \mathrm{pH}\left(\mathrm{H}_{2} \mathrm{O}\right)=4,0 ; \mathrm{Ca}^{2+}=$ $0,2 \mathrm{cmol}_{\mathrm{c}} \mathrm{dm}^{-3} ; \mathrm{Mg}^{2+}=0,1 \mathrm{cmol}_{\mathrm{c}} \mathrm{dm}^{-3} ; \mathrm{P}($ Mehlich -1$)=$ $1,0 \mathrm{mg} \mathrm{dm}^{-3}, \mathrm{~K}^{+}=11 \mathrm{mg} \mathrm{dm}{ }^{-3} ; \mathrm{Al}^{3+}=0,5 \mathrm{cmol}_{\mathrm{c}} \mathrm{dm}^{-3} \mathrm{e}$ $\mathrm{C}$ orgânico $=18,0 \mathrm{~g} \mathrm{~kg}^{-1}$. Os teores de argila, silte e areia foram, respectivamente, de 270, $290 \mathrm{e} 440 \mathrm{~g} \mathrm{~kg}^{-1}$.

\section{Implantação e condução do experimento}

Antes da implantação do experimento em campo, foi realizada, em novembro de 1991, a calagem do solo da área experimental, com o objetivo de elevar a saturação por bases do solo a $60 \%$, com o corretivo (calcário dolomítico) incorporado na camada de $0-0,2 \mathrm{~m}$ de profundidade. A implantação do experimento no campo, caracterizada pelo plantio das mudas do cafeeiro, foi realizada em janeiro de 1992, sulcando-se o solo de acordo com os espaçamentos estudados, utilizando no plantio o cultivar Catuaí Vermelho IAC44, com uma planta por cova. Durante a condução do experimento (1992 a 2004), o cafeeiro foi mantido livre de plantas invasoras por meio de capinas manuais (cinco a seis capinas por ano) e aplicações de herbicidas, com os resíduos vegetais depositados nas entrelinhas de plantio, de modo que o solo sob a projeção da copa ficasse descoberto durante a maior parte do ano. A partir de 1994, no mês que antecedia à colheita foi realizada a arruação, prática que consiste em concentrar os resíduos vegetais e parte da camada mais superior do solo da projeção da copa nas entrelinhas de plantio. Os resíduos vegetais depositados na entrelinha não foram retornados para a projeção da copa após o término da colheita. Após 10 anos de condução do experimento (julho de 2002), procedeu-se à recepa das plantas a $40 \mathrm{~cm}$ de altura do solo. Quatro meses após a recepa, foi feita a desbrota, deixando-se duas hastes por tronco, no sentido da linha de plantio. Todos os resíduos culturais oriundos dessas práticas foram triturados e depositados nas entrelinhas de plantio, caracterizando, assim, um sistema de manejo dos resíduos culturais na entrelinha (com a presença dos resíduos) e outro na projeção da copa (solo descoberto).

A correção da acidez do solo, quando necessária, e as adubações para implantação, formação, produção e formação pós-recepa do cafeeiro foram efetuadas com base na análise química do solo, seguindo-se as recomendações contidas em CFSEMG (1989). A altura das plantas de cafeeiro variou de 2,87 a $3,11 \mathrm{~m}$ (medições realizadas em 2002), e os índices médios de produtividade variaram em função do espaçamento de plantio adotado, estando dentro da faixa de 28 a 60 sacas beneficiadas de $60 \mathrm{~kg} \mathrm{ha}^{-1}$. Esses resultados foram referentes às colheitas efetuadas entre $1994 \mathrm{e}$ 2002. Os dados de altura de plantas e produtividade do cafeeiro foram compilados de Pereira (2004).

Os tratamentos avaliados consistiram da combinação de quatro espaçamentos entre linhas (2,0; $2,5 ; 3,0 ;$ e $3,5 \mathrm{~m})$, três espaçamentos entre plantas $(0,5 ; 0,75 ;$ e $1,0 \mathrm{~m})$ e dois sistemas de manejo dos resíduos culturais (entrelinha - EL e projeção da copa -PC), totalizando 24 tratamentos, dispostos no campo em blocos ao acaso, em esquema fatorial $4 \times 3 \times 2$, com três repetições. As parcelas experimentais mediam $12 \mathrm{~m}$ de comprimento e possuíam três linhas de cafeeiro, cujas distâncias entre si variaram dependendo do tratamento estudado. A parcela útil 
considerada na etapa de coleta das amostras de solo foi a linha central (interna), uma vez que esta sofreu a influência tanto do adensamento entre linhas como entre plantas. A densidade populacional variou, de acordo com o arranjo das plantas no campo, de 2.857 a 10.000 plantas por hectare.

\section{Amostragem do solo e preparo das amostras}

A amostragem do solo foi realizada em dezembro de 2003. Em cada parcela experimental, as amostras foram coletadas na projeção da copa (PC) e na entrelinha de cultivo (EL), onde eram depositados todos os resíduos culturais e os provenientes das capinas realizadas na projeção da copa do cafeeiro. Para avaliação dos teores de C orgânico (CO) e N total (NT), foram retiradas amostras de solo nas profundidades de 0-0,05, 0-0,1, 0,1-0,2 e 0,2-0,4 m. Para cada tratamento, dentro da parcela de cada bloco, nos dois sistemas de manejos dos resíduos (EL e PC), foi retirada uma amostra composta oriunda de cinco amostras simples coletadas ao acaso. Numa área sob mata, numa distância aproximada de $1 \mathrm{~km}$ do experimento, com a mesma classe de solo e sem histórico de intervenção humana, foram coletadas amostras de solo nas mesmas profundidades daquelas amostradas na área experimental, que foram utilizadas como referência de área sob vegetação natural.

As amostras destinadas às análises de CO e NT foram acondicionadas em sacos plásticos e conduzidas para o laboratório, onde foram secas ao ar, destorroadas, trituradas em almofariz e passadas em peneira de malha de $0,21 \mathrm{~mm}$.

\section{Análises químicas}

\section{Carbono orgânico do solo}

Os teores de $\mathrm{CO}$ do solo foram determinados pelo método descrito em Yeomans \& Bremner (1988), após a digestão de $0,3 \mathrm{~g}$ de solo com $5 \mathrm{~mL}$ de $\mathrm{K}_{2} \mathrm{Cr}_{2} \mathrm{O}_{7}$ $0,167 \mathrm{~mol} \mathrm{~L}^{-1}$ e $10 \mathrm{~mL}$ de $\mathrm{H}_{2} \mathrm{SO}_{4}$ p.a., por $30 \mathrm{~min}$ a $170{ }^{\circ} \mathrm{C}$, em bloco digestor de 40 provas. Após o resfriamento em temperatura ambiente, os extratos foram transferidos para erlenmeyers de $125 \mathrm{~mL}$, utilizando-se água destilada suficiente para obter um volume final de aproximadamente $75 \mathrm{~mL}$. Em seguida, a cada erlenmeyer, foram adicionados $5 \mathrm{~mL}$ de $\mathrm{H}_{3} \mathrm{PO}_{4}$ p.a., procedendo-se à titulação com solução de $\mathrm{Fe}\left(\mathrm{NH}_{4}\right)_{2}\left(\mathrm{SO}_{4}\right)_{2} \cdot 6 \mathrm{H}_{2} \mathrm{O} 0,4 \mathrm{~mol} \mathrm{~L}^{-1}$ (sal de Mohr), utilizando como indicador a solução ácida de difenilamina $1 \%$. Paralelamente, foram realizadas provas em branco, com ou sem aquecimento.

\section{Nitrogênio total do solo}

Os teores de NT no solo foram determinados seguindo marcha analítica descrita em Bremner (1996), que envolve o uso de uma mistura digestora à base de $\mathrm{K}_{2} \mathrm{SO}_{4}, \mathrm{CuSO}_{4}$ e Se. A cada amostra de $0,1 \mathrm{~g}$ de solo, foram adicionados $1,1 \mathrm{~g}$ da mistura digestora e 3,0 mL de $\mathrm{H}_{2} \mathrm{SO}_{4}$ p.a. A digestão foi feita a $350{ }^{\circ} \mathrm{C}$, e o $\mathrm{N}$ evoluído por destilação a vapor foi recolhido em uma solução de $\mathrm{H}_{3} \mathrm{BO}_{3}\left(20 \mathrm{~g} \mathrm{~L}^{-1}\right)$, misturada a uma solução de verde de bromocresol e vermelho de metila e titulado com solução de $\mathrm{HCl} 0,01 \mathrm{~mol} \mathrm{~L}^{-1}$.

Após as análises químicas, calculou-se a relação CO/NT do solo.

\section{Análise estatística}

Os dados dos teores de CO e NT e da relação CO/ NT foram submetidos à análise de variância para verificação, em cada profundidade de solo, dos efeitos dos espaçamentos entre linhas, entre plantas e dos dois sistemas de manejo dos resíduos culturais (EL e PC). Os dados levantados na área sob vegetação natural foram excluídos da análise estatística, pelo fato de o local não compor o desenho experimental usado para avaliar o efeito dos espaçamentos de plantio de cafeeiro sobre os atributos estudados. As médias foram comparadas pelo teste de Scott-Knott a $5 \%$, utilizando-se o aplicativo computacional SISVAR (Ferreira, 2000).

\section{RESULTADOS E DISCUSSÃO}

Os maiores teores de CO foram obtidos na camada de 0-0,05 m de solo, tanto para as amostras coletadas na EL como para aquelas coletadas na PC do cafeeiro, havendo, em todos os espaçamentos de plantio (com exceção do espaçamento de 2,0 x 0,75 m), maior teor de $\mathrm{CO}$ na EL, em relação à $\mathrm{PC}$ (Quadro 1 ). Na EL (0-0,05 m), no espaçamento de 1,0 m entre plantas, os teores de CO não foram influenciados pelos diferentes espaçamentos entre linhas adotados. No entanto, quando o espaçamento entre plantas foi de $0,75 \mathrm{~m}$, os maiores teores de $\mathrm{CO}$ ocorreram nos espaçamentos entre linhas maiores que $2,0 \mathrm{~m}$. Na camada de solo de 0-0,1 m, na EL, mesmo com as respostas diferenciadas dos teores de $\mathrm{CO}$ quanto ao aumento do espaçamento entre linhas, nos espaçamentos de 0,5 e 1,0 m entre plantas, os maiores teores de CO foram observados quando as linhas de plantio distanciavam-se 3,5 m. Os teores de $\mathrm{CO}$, na profundidade de solo de 0-0,1 m, não foram influenciados pelos espaçamentos de plantio avaliados quando as amostras foram coletadas na PC, sendo observada diferença significativa somente na camada de 0-0,05 m, com o maior teor $\left(30,1 \mathrm{~g} \mathrm{~kg}^{-1}\right)$ ocorrendo no espaçamento de plantio de $3,5 \times 0,5 \mathrm{~m}$.

As maiores alterações nos teores de CO ocorreram nas camadas superficiais do solo, com os maiores valores observados na EL e no espaçamento de plantio de 3,5 x 0,75 m (Quadro 1). Esse resultado pode estar associado ao maior aporte de resíduos de plantas invasoras nas entrelinhas deste espaçamento, 
Quadro 1. Teores de carbono orgânico em diferentes profundidades de um Latossolo cultivado com cafeeiro em quatro espaçamentos entre linhas, três entre plantas e em dois sistemas de manejo dos resíduos culturais

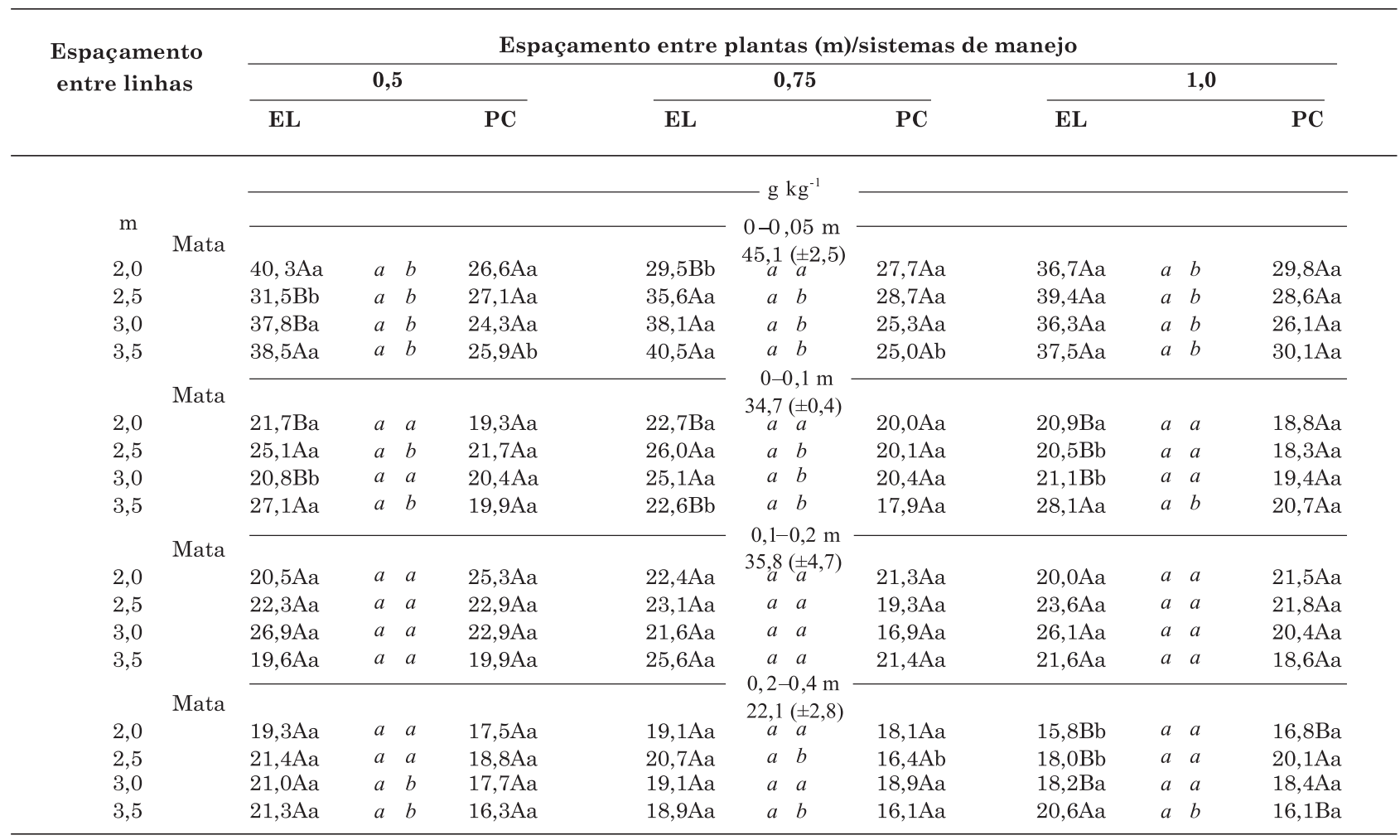

Valores entre parênteses referem-se ao erro-padrão da média $(n=3)$. Médias seguidas de letras iguais não diferem entre si pelo teste de Scott-Knott $(\mathrm{p} \leq$ 0,05). As letras minúsculas centrais em itálico, na linha, comparam os teores de CO entre os sistemas de manejo dos resíduos culturais (EL e PC) dentro de cada espaçamento entre plantas e entre linhas; as letras maiúsculas, na coluna, comparam os teores de CO entre os espaçamentos entre linhas dentro de cada espaçamento entre plantas e sistema de manejo; letras minúsculas, na linha, comparam os teores de CO entre os espaçamentos entre plantas dentro de cada espaçamento entre linhas e sistema de manejo. EL: entrelinhas; PC: projeção das copas dos cafeeiros.

compensando a menor quantidade de resíduos culturais depositados naquele local, oriundos da poda e recepa dos cafeeiros. Os resultados obtidos indicam que o elevado aporte de resíduos culturais na lavoura cafeeira, a reduzida perda de solo por erosão e a ausência ou menor revolvimento do solo podem contribuir para aumentar ou preservar os teores de $\mathrm{CO}$ do solo. O decréscimo nas quantidades de $\mathrm{CO}$ perdidas por erosão e lixiviação explica, do mesmo modo, o acréscimo de CO na EL do cafeeiro (Fernandes et al., 1997).

As reduções médias nos teores de $\mathrm{CO}$ em todos os espaçamentos de plantio, na profundidade de 0-0,05 m em relação à área de mata, foram de 18 e 40 \% para as amostras coletadas na EL e na PC, respectivamente, o que está de acordo com os resultados obtidos por Tiessen et al. (1994) e Mielniczuk et al. (2003). Segundo esses autores, em áreas cultivadas dos trópicos, as elevadas taxas de perda de MOS resultam em redução de cerca de 50 \% do conteúdo original da MO em relação ao mesmo solo sob vegetação natural, em menos de 10 anos de cultivo, principalmente nos sistemas com baixo aporte de resíduos vegetais. Os resultados obtidos indicam que o maior aporte de resíduos culturais na EL do cafeeiro pode acarretar, ao longo do tempo, maior armazenamento de $\mathrm{CO}$ no solo, superando os teores encontrados no mesmo solo na $\mathrm{PC}$, onde há menor deposição de resíduos vegetais.

Assim, a diminuição nos teores de CO na PC, em relação à EL, pode ser explicada pelo fato de a maior parte dos resíduos orgânicos ser depositada na EL, o que, associado ao maior revolvimento do solo $(0-0,05 \mathrm{~m})$ pelas capinas constantes realizadas na $\mathrm{PC}$, contribuiu para a decomposição mais acelerada da MOS. Na profundidade de solo de 0,1-0,2 m, não foram observados efeitos significativos entre os espaçamentos de plantio e manejo dos resíduos culturais nos teores de CO. Na profundidade de $0,2-$ $0,4 \mathrm{~m}$, houve diferença significativa entre os espaçamentos entre linhas apenas no espaçamento entre plantas de $1,0 \mathrm{~m}$, com o maior valor sendo observado no espaçamento de 3,5 m. Nessa mesma profundidade de solo, o teor de $\mathrm{CO}$ foi maior no espaçamento entre plantas de $0,5 \mathrm{~m}$, quando a distância entre linhas foi de 2,5 m. Os resultados 
apresentados evidenciaram que os maiores efeitos dos espaçamentos de plantio e manejo dos resíduos culturais ocorreram nas camadas superficiais do solo, ou seja, até $0,1 \mathrm{~m}$.

Os teores de NT do solo não foram influenciados pelos diferentes espaçamentos entre linhas e entre plantas na profundidade de 0-0,05 $\mathrm{cm}$ (Quadro 2). As diferenças ocorreram entre os sistemas de manejo dos resíduos culturais nos espaçamentos de plantio de $3,0 \times 0,5,3,0 \times 0,75,3,0 \times 1,0,3,5 \times 0,75$ e $3,5 \times 1,0 \mathrm{~m}$, com os maiores valores observados na EL, evidenciando que as diferenças ocorreram quando as distâncias entre as fileiras dos cafeeiros foram maiores ou iguais a $3 \mathrm{~m}$. Na camada de solo de $0-0,1 \mathrm{~m}$, nas amostras coletadas na EL, os maiores teores de NT foram observados nos espaçamentos de 2,5 e 3,0 m entre linhas, no espaçamento de $0,75 \mathrm{~m}$ entre plantas, e no espaçamento de 3,5 m entre linhas, e de 1,0 m entre plantas.

As diferenças nos teores de NT entre o solo da PC e o solo sob mata variaram de $8 \%(3,5 \times 1,0 \mathrm{~m})$ a $33 \%$ $(2,0 \times 1,0,2,5 \times 0,75$ e $3,5 \times 0,5 \mathrm{~m})$, o que corresponde a uma quantidade de NT variando de 0,6 a $2 \mathrm{t} \mathrm{ha}^{-1}$, na camada de solo de 0-0,05 $\mathrm{m}$ de profundidade. Somente nas amostras coletadas na EL (0-0,05 m) os teores de NT foram superiores à área de mata em todos os tratamentos, com aumento médio, em relação à área de mata, de $25 \%$ (ou $2 \mathrm{t} \mathrm{ha}^{-1}$ de NT), mostrando o efeito positivo dos resíduos vegetais naquele local. Em razão de mais de $95 \%$ do NT estar presente no solo na forma orgânica (Camargo et al., 1999), os maiores teores de MO na profundidade de 0-0,05 m, evidenciados pelos teores de CO (Quadro 1), justificam os teores de NT na EL. Tanto no solo sob mata como no cultivado com cafeeiro houve tendência de diminuição nos teores de NT com o aumento da profundidade do solo, ocorrendo, do mesmo modo como foi observado para o $\mathrm{CO}$, os maiores teores na profundidade de 0-0,05 m. Acredita-se que o fator que mais tenha contribuído para aumentar os teores de NT seja a menor taxa de decomposição da MO na EL. Tal suposição se justifica pelo fato de o manejo do solo da EL ser, nos últimos 11 anos (1992/2003), bastante conservacionista, caracterizando-se pelo pouco revolvimento do solo e pela permanência dos restos culturais da lavoura e das plantas invasoras sobre o solo na EL.

Quadro 2. Teores de nitrogênio total em diferentes profundidades de um Latossolo cultivado com cafeeiro em quatro espaçamentos entre linhas, três entre plantas e em dois sistemas de manejo dos resíduos culturais

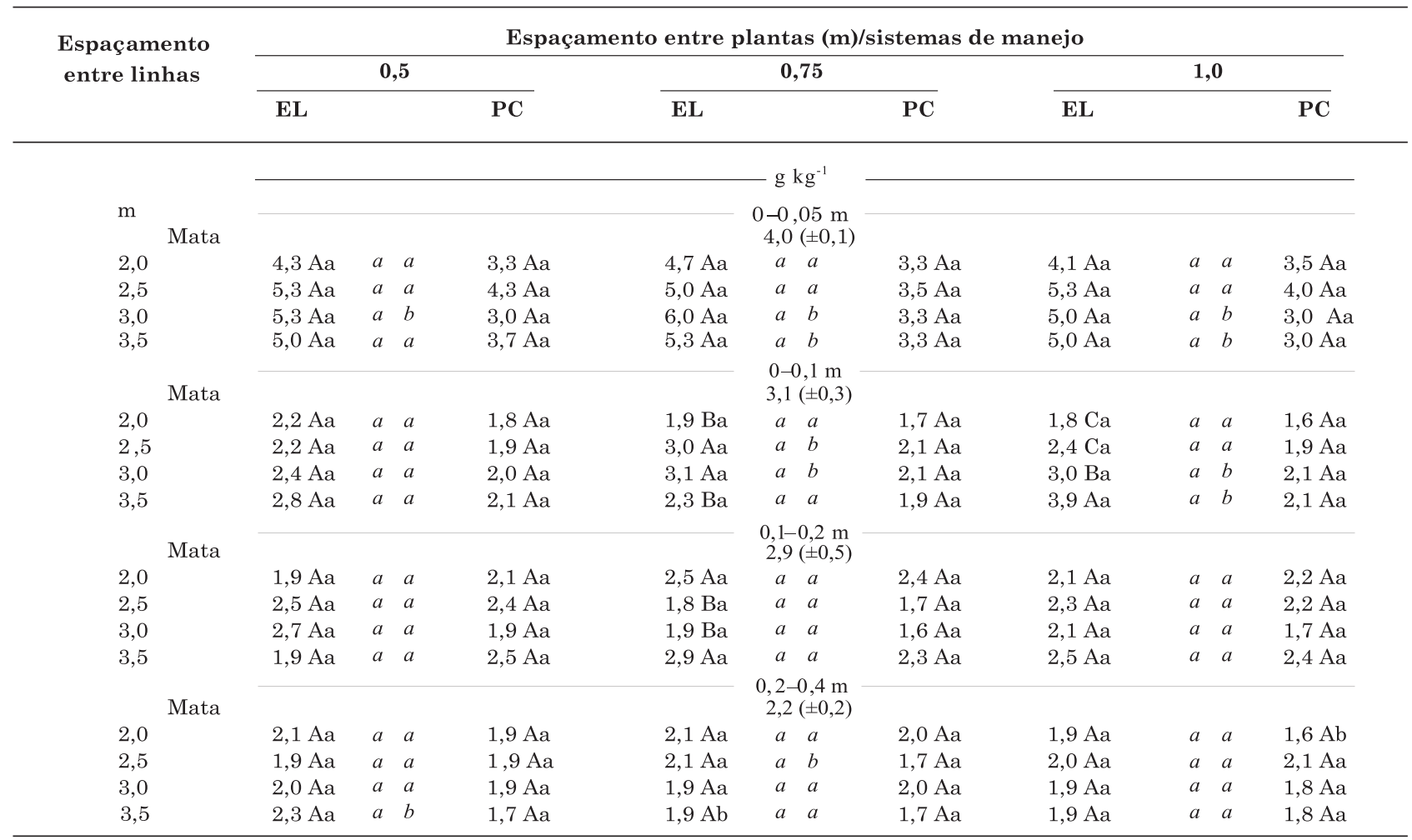

Valores entre parênteses referem-se ao erro-padrão da média $(n=3)$. Médias seguidas de letras iguais não diferem entre si pelo teste de Scott-Knott $(\mathrm{p} \leq 0,05)$. As letras minúsculas centrais em itálico, na linha, comparam os teores de NT entre os sistemas de manejo dos resíduos culturais (EL e PC) dentro de cada espaçamento entre plantas e entre linhas; as letras maiúsculas, na coluna, comparam os teores de NT entre os espaçamentos entre linhas dentro de cada espaçamento entre plantas e sistema de manejo; letras minúsculas, na linha, comparam os teores de NT entre os espaçamentos entre plantas dentro de cada espaçamento entre linhas e sistema de manejo. EL: entrelinhas; PC: projeção das copas dos cafeeiros. 
Segundo Camargo et al. (1999), os teores de NT dependem de fatores como temperatura, umidade, aeração, quantidade e natureza do material orgânico depositado no solo. No solo de mata, a fonte de resíduos orgânicos está associada à deposição natural de restos de plantas, que alcançam o solo na forma de folhas, galhos e outros fragmentos orgânicos, bem como substâncias orgânicas derivadas da decomposição das raízes (Pohlman \& Mccoll, 1988). Assim, os menores teores de NT encontrados no solo sob mata $(0-0,05 \mathrm{~m})$, em relação ao solo da EL do cafeeiro, podem estar associados à qualidade dos resíduos adicionados ao solo, que, provavelmente, apresentam maiores proporções de polímeros orgânicos recalcitrantes (ligninas, suberinas, resinas e ceras), portanto menos suscetíveis à decomposição pela microbiota do solo.

Em regiões tropicais úmidas, de acordo com Stevenson (1994), os teores de NT de solos não perturbados tendem a cair rapidamente quando o solo passa a ser cultivado, sendo esse decréscimo maior nos casos em que os restos culturais são removidos do solo, como ocorrido neste estudo, nas amostras coletadas na PC. Os aumentos nos teores de NT notados na EL podem ser explicados pela maior presença de vegetação de gramíneas (plantas invasoras), as quais, em razão de uma alta deposição de MO no solo, da elevada alocação de fotossintatos para o sistema radicular e do maior coeficiente de humificação do $\mathrm{C}$ adicionado ao solo (Boddey et al., 2001; Pillon et al., 2001), podem ter acarretado o aumento nos teores de NT, como ocorreu com os teores de CO.

As maiores proporções do $\mathrm{CO}$ e do NT foram observadas nas camadas superficiais do solo. Considerando os teores de CO e NT avaliados em superfície e em camadas mais profundas do solo, nos diferentes tratamentos e nos sistemas de manejo dos resíduos (EL e PC), verificou-se que, a 0,1 m de solo, foram armazenados, em média, $57 \%$ do $\mathrm{CO}$ e $62 \%$ do NT. Cerri (1989), em estudo conduzido em solos da Bacia Amazônica, concluiu que 41,8 \% do NT estavam armazenados até $0,2 \mathrm{~m}$ do solo, provavelmente em razão do maior acúmulo de material orgânico nos horizontes superficiais, tanto no solo sob vegetação natural quanto no cultivado.

Analisando os espaçamentos entre plantas, os maiores valores da relação CO/NT ocorreram entre 0,5 e $0,75 \mathrm{~m}$ no espaçamento entre linhas de 2,0, para amostras coletadas na EL, na profundidade de 0-0,05 m(Quadro 3).

Quadro 3. Relação carbono orgânico/nitrogênio total (CO/NT) em diferentes profundidades de um Latossolo cultivado com cafeeiro em quatro espaçamentos entre linhas, três entre plantas e em dois sistema de manejo dos resíduos culturais, no sul de Minas Gerais

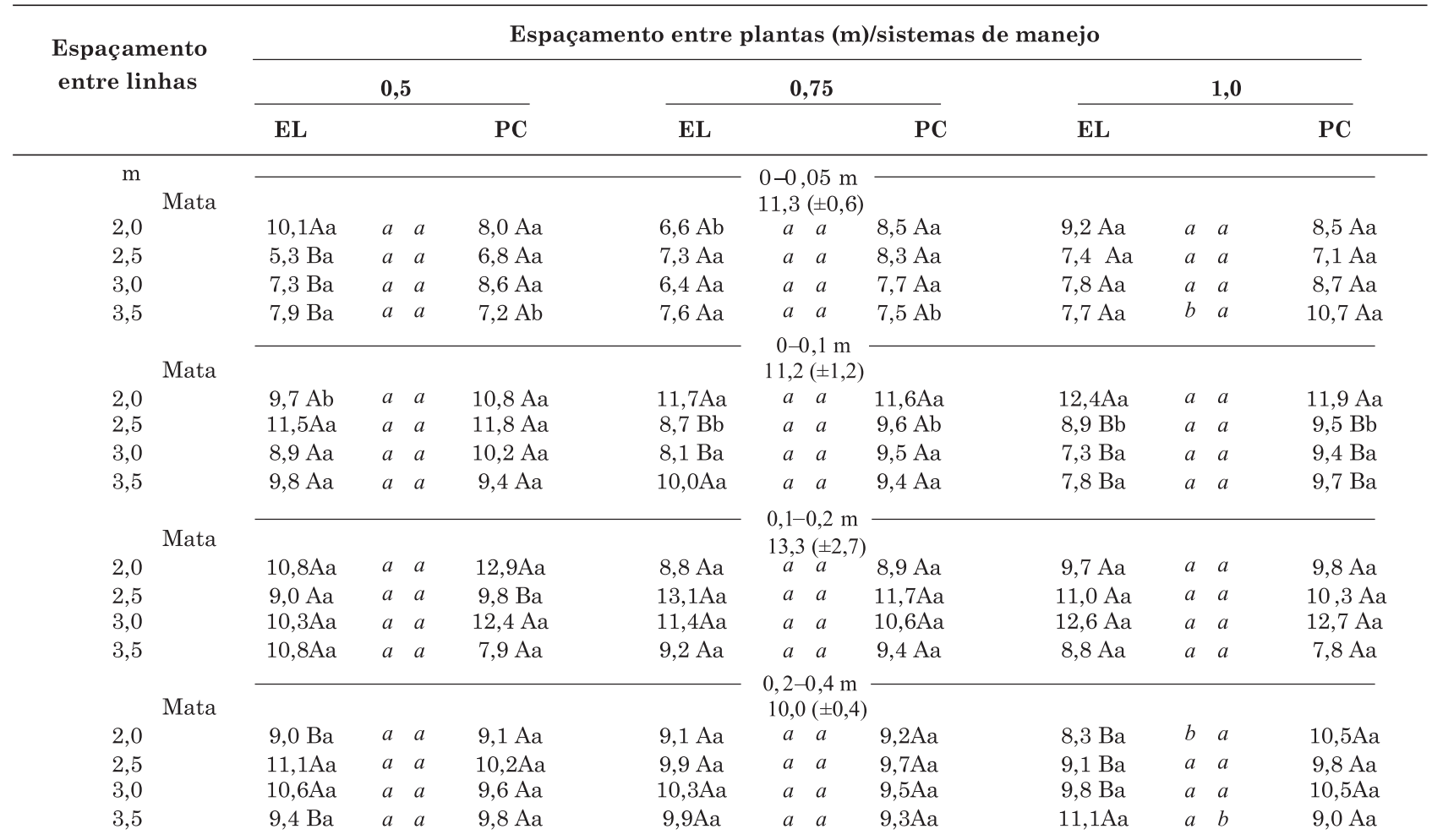

Valores entre parênteses referem-se ao erro-padrão da média $(n=3)$. Médias seguidas de letras iguais não diferem entre si pelo teste de Scott-Knott $(\mathrm{p} \leq$ 0,05). As letras minúsculas centrais em itálico, na linha, comparam os teores de NT entre os sistemas de manejo dos resíduos culturais (EL e PC) dentro de cada espaçamento entre plantas e entre linhas; as letras maiúsculas, na coluna, comparam os teores de NT entre os espaçamentos entre linhas dentro de cada espaçamento entre plantas e sistema de manejo; letras minúsculas, na linha, comparam os teores de NT entre os espaçamentos entre plantas dentro de cada espaçamento entre linhas e sistema de manejo. EL: entrelinhas; PC: projeção das copas dos cafeeiros. 
Na profundidade de $0-0,1 \mathrm{~m}$, na EL, os maiores valores da relação $\mathrm{CO} / \mathrm{NT}$ ocorreram nos espaçamentos entre plantas de 0,75 e $1,0 \mathrm{~m}$, no espaçamento entre linhas de $2,0 \mathrm{~m}$, e $0,5 \mathrm{~m}$ entre plantas, no espaçamento entre linhas de 2,5 m. Com exceção dos espaçamentos de plantio de $3,5 \times 1,0 \mathrm{~m}$, na profundidade de $0-0,05 \mathrm{~m}$, e 2,0 × 1,0 e $3,5 \times 1,0 \mathrm{~m}$, na profundidade de $0,2-0,4 \mathrm{~m}$, não foram observadas diferenças significativas entre os sistemas de manejo dos resíduos. Para solos tropicais não revolvidos, na camada de solo de $0-0,2 \mathrm{~m}$, a relação $\mathrm{CO} / \mathrm{NT}$ varia normalmente de 10 a 15/1 (Stevenson, 1994).

Os baixos valores de relação CO/NT no solo sob cafeeiro podem ser conseqüência da menor relação $\mathrm{CO} /$ NT dos resíduos da cultura depositados no solo, em virtude das adubações nitrogenadas efetuadas na lavoura cafeeira, o que pode ter contribuído também para a redução da relação $\mathrm{CO} / \mathrm{NT}$ da $\mathrm{MO}$ do solo sob cafeeiro. Outro fator a ser considerado são as prováveis perdas mais rápidas de $\mathrm{CO}$ em relação ao NT em sistemas com adições freqüentes de resíduos orgânicos. Sampaio et al. (1990), estudando a decomposição da palha de milho, verificaram que a relação $\mathrm{CO} / \mathrm{NT}$ do solo decresceu de 22 para 8 a 10 em três profundidades estudadas, num período de dois anos. Segundo os autores, isso resulta da perda mais acelerada de $\mathrm{CO}$ que do NT, principalmente na fase inicial da mineralização, em que as taxas de desaparecimento das formas mais lábeis do $\mathrm{CO}$ foram de duas a três vezes maiores que as de NT.

Na profundidade de solo de $0,2-0,4 \mathrm{~m}$, a relação $\mathrm{CO} / \mathrm{NT}$ na área de mata esteve próxima ou abaixo da observada na área cultivada, o que pode estar associado ao fato de os tratamentos estudados terem proporcionado poucas alterações significativas nos teores de CO e NT na profundidade de $0,2-0,4 \mathrm{~m}$. Na área cultivada, as menores relações $\mathrm{CO} / \mathrm{NT}$ nas camadas superficiais $(0-0,05$ e $0-0,1 \mathrm{~m})$ podem ser explicadas pelo fato de o $\mathrm{N}$ orgânico permanecer em sua maior parte nessas camadas em relação às camadas mais profundas, onde os teores de $\mathrm{CO}$ reduziram-se em menor proporção.

A diferença na relação $\mathrm{CO} / \mathrm{NT}$ entre os diferentes espaçamentos de plantio do cafeeiro foi mais acentuada na EL que na PC, evidenciando que a diferenciação no manejo dos resíduos culturais altera significativamente o quociente (Quadro 3). Na média, nas quatro profundidades, em relação ao solo de mata, houve decréscimo de 10,9\% na relação CO/NT nas amostras coletadas na EL, ao passo que na PC verificou-se redução de 16,2 \%.

\section{CONCLUSÕES}

1. O cultivo do solo com cafeeiro promoveu redução nos teores de $\mathrm{CO}$ até a profundidade de $0,2 \mathrm{~m}$, em relação à área não cultivada sob vegetação nativa (mata). Abaixo da camada de 0,2 m, os teores de CO e NT e a relação $\mathrm{CO} / \mathrm{NT}$ do solo sob cafeeiro apresentaram-se próximos aos do solo de mata.

2. Nas camadas superficiais de solo, até $0,1 \mathrm{~m}$ de profundidade, os teores de CO nas amostras da entrelinha foram maiores do que os das amostras da projeção da copa do cafeeiro. Há, nessas camadas de solo, em geral, uma tendência de aumento dos teores de $\mathrm{CO}$ à medida que se aumenta o espaçamento entre linhas de cafeeiro.

3. O acúmulo dos resíduos vegetais, o menor revolvimento do solo e os maiores teores de MO na EL favoreceram, em relação à $\mathrm{PC}$, a ocorrência de maiores teores de CO e NT. Na profundidade de 0-0,1 m, no espaçamento entre plantas de $1,0 \mathrm{~m}$, os maiores teores de CO e NT foram observados no espaçamento entre linhas de $3,5 \mathrm{~m}$.

\section{AGRADECIMENTOS}

À equipe da Estação Experimental da EPAMIGMachado, MG, pela ajuda na coleta das amostras e na condução e manutenção do experimento avaliado; ao Consórcio Brasileiro de Pesquisa e Desenvolvimento/ Café, à Embrapa Café e à Fundação de Amparo à Pesquisa do Estado de Minas Gerais, pela concessão de fomento utilizado no custeio das ações de pesquisa (Projeto 19.2003.133.03 e Projeto EDT 2222/03, respectivamente).

\section{LITERATURA CITADA}

ARATO, H.D.; MARTINS, S.V. \& FERRARI, S.H.S. Produção e decomposição de serapilheira em um sistema agroflorestal implantado para recuperação de área degradada em Viçosa-MG. R. Árvore, 27:597-603, 2003.

BEER, J. Litter production and nutrient cycling in coffee (Coffea arabica) or cacao (Theobroma cacao) plantations with shade trees. Agrofor. Syst., 7:103-114, 1998.

BODDEY, R.M.; ALVES, B.J.R.; OLIVEIRA, O.C. \& URGUIGA, S. Potencial para acumulação e seqüestro de carbono em pastagens de Brachiaria. In: LIMA, M.A.; CABRAL, O.M.R. \& MIGUEZ, J.D.G., eds. Mudanças climáticas globais e a agropecuária brasileira. Jaguariúna, Embrapa Meio Ambiente, 2001. p.213-229.

BREMNER, J.M. Nitrogen total. In: SPARKS, D.L., ed. Methods of soil analysis. Part 3. Madison, America Society of Agronomy, 1996. p.1085-1121 (SSSA Book Series, 5).

CAMARGO, F.A.C.; GIANELLO, C.; TEDESCO, M.J. \& VIDOR, C. Nitrogênio orgânico do solo. In: SANTOS, G.A. \& CAMARGO, F.A.O., eds. Fundamentos da matéria orgânica do solo. Porto Alegre, Genesis, 1999. p.117-137.

CERRI, C.C. Dinâmica da matéria orgânica em solos de pastagem. In: SIMPÓSIO SOBRE ECOSSISTEMAS DE PASTAGEM, Jaboticabal, 1989. Anais. Jaboticabal, FCAVJ, 1989. p.135-147. 
COMISSÃO DE FERTILIDADE DO SOLO DO ESTADO DE MINAS GERAIS - CFSEMG. Recomendações para o uso de corretivos e fertilizantes em Minas Gerais, $4^{\mathrm{a}}$ aproximação. Lavras, Universidade Federal de Lavras, 1989. $176 \mathrm{p}$.

D'ANDRÉA, A.F.; SILVA, M.L.N.; CURI, N. \& GUILHERME, L.R.G. Estoques de carbono e nitrogênio e formas de nitrogênio mineral em um solo submetido a diferentes sistemas de manejo. Pesq. Agropec. Bras., 39:179-186, 2004.

FERNANDES, E.C.M.; MOTAVALLI, P.P. \& CASTILLA, C. Management control of soil organic matter dynamics in tropical land-use systems. Geoderma, 79:49-67, 1997.

FERREIRA, D.F. Análises estatísticas por meio do SISVAR para Windows 4. 0. In: REUNIÃO ANUAL DA REGIÃO BRASILEIRA DA SOCIEDADE INTERNACIONAL DE BIOMETRIA, 45., São Carlos, 2000. Anais. São Carlos, Universidade Federal de São Carlos, 2000. p.255-258.

LAL, R. World cropland soils as a source or sink for atmospheric carbon. Adv. Agron., 71:145-191, 2001.

LONGO, R.M. \& ESPÍNDOLA, C.R. C-orgânico, N-total e substâncias húmicas sob influência da introdução de pastagens (Brachiaria sp.) em áreas de Cerrado e Floresta Amazônica. R. Bras. Ci. Solo, 24:723-729. 2000.

MARCHIORI JÚNIOR, M. \& MELO, W.J. Alterações na matéria orgânica e na biomassa microbiana em solo de mata natural submetido a diferentes manejos. Pesq. Agropec. Bras., 35:1177-1182, 2000.

MIELNICZUK, J.; BAYER, C.; VEZZANI, F.M.; LOVATO, T.; FERNANDES, F.F. \& DEBARBA, L. Manejo de solo e culturas e sua relação com os estoques de carbono e nitrogênio do solo. In: CURI, N.; MARQUES, J.J.; GUILHERME, L.R.G.; LIMA, J.M.; LOPES, A.S. \& ALVAREZ V., V.H. Tópicos em ciência do solo. Viçosa, MG, Sociedade Brasileira de Ciência do Solo, 2003. v.3. p.209-248.
PAVAN, M.A. \& CHAVES, J.C.D. Influência da densidade de plantio de cafeeiro sobre a fertilidade do solo. In: SIMPÓSIO INTERNACIONAL SOBRE CAFEEIRO ADENSADO, Londrina, 1996. Anais. Londrina, IAPAR/ CNPq, 1996. p.76-89.

PEREIRA, S.P. Caracterização fenológica e reprodutiva de cafeeiros (Coffea arabica L.) em diversos espaçamentos, antes e após recepa. Lavras, Universidade Federal de Lavras, 2004. 105p. (Tese de Mestrado)

PILLON, C.N.; MIELNICZUK, J. \& MARTIN NETO, L. Seqüestro de carbono por sistemas de manejo do solo e seus reflexos sobre o efeito estufa. In: ENCONTRO BRASILEIRO DE SUBSTÂNCIAS HÚMICAS, 4., Viçosa, 2001. Anais. Viçosa, MG, Universidade Federal de Viçosa, 2001. p.20-22.

POHLMAN, A.A. \& MCCOLL, J.G. Soluble organics from forest litter and their role in metal dissolution. Soil Sci. Soc. Am. J., 52:265-271, 1988.

SAMPAIO, E.V.S.; SALCEDO, I.H.; LIMA JUNIOR; M.A. \& BETTANY, J. Decomposição de palha de milho $\left({ }^{14} \mathrm{C}-{ }^{15} \mathrm{~N}\right)$ incorporada a três profundidades em um Latossolo Vermelho-Amarelo de Pernambuco. R. Bras. Ci. Solo, 14:269-276, 1990.

SILVA, J.E.; LEMAINSKI, J. \& RESCK, D.V.S. Perdas de matéria orgânica e suas relações com a capacidade de troca catiônica em solos da região de cerrados do oeste baiano. R. Bras. Ci. Solo, 18:541-547, 1994.

STEVENSON, F.J. Humus chemistry: Genesis, composition, reactions. 2.ed. New York, John Wiley \& Sons, 1994. 496p.

TIESSEN, H.; CUEVAS, E. \& CHACON, P. The role of soil organic matter stability in soil fertility and agricultural potential. Nature, 371:783-785, 1994.

YEOMANS, J.C. \& BREMNER, J.M. A rapid and precise method for routine determination of organic carbon in soil. Comm. Soil Sci. Plant Anal., 19:1467-1476, 1988.

ZINN, Y.L.; LAL, R. \& RESCK, D.V.S. Changes in soil organic carbon stocks under agriculture in Brazil. Soil Till. Res., $84: 28-40,2005$. 